\title{
Sưstalinable Chemistry \& Engineering \\ Homogeneously Dispersed Zerovalent Iron Nanoparticles Supported on Hydrochar-Derived Porous Carbon: Simple, in Situ Synthesis and Use for Dechlorination of PCBs
}

\author{
Zhengang Liu, ${ }^{*}{ }^{\dagger}$ Fang Zhang, ${ }^{\ddagger}$ S. Kent Hoekman, ${ }^{\S}$ Tingting Liu, ${ }^{\dagger}$ Chao Gai, ${ }^{\dagger}$ and Nana Peng ${ }^{\dagger}$ \\ ${ }^{\dagger}$ Research Center for Eco-Environmental Sciences, Chinese Academy of Sciences, 18 Shuangqing Road, Beijing 100085, China \\ ${ }^{\ddagger}$ Key Laboratory of Cluster Science of Ministry of Education, School of Chemistry, Beijing Institute of Technology, Beijing 100081, \\ China \\ ${ }^{\S}$ Division of Atmospheric Sciences, Desert Research Institute (DRI), 2215 Raggio Parkway, Reno, Nevada 89512, United States
}

Supporting Information

ABSTRACT: Herein, we have developed a simple and effective strategy for in situ preparation of nanoscale zerovalent iron (NZVI) supported on porous carbon (PC) using renewable hydrochar as the carbon precursor. Physicochemical properties of the resultant NZVI/PC composites were characterized by XRD, SEM-EDS, TEM, and BET, and the effectiveness of these composites was evaluated for the remediation of PCBcontaminated water. Results showed that the iron ions were uniformly dispersed within the hydrochar matrix and serve as an activation agent for the hydrochar during a subsequent pyrolysis process. The iron is reduced in situ to NZVI with diameters of $8.5-10 \mathrm{~nm}$, without requiring an additional reducing agent. At temperatures of $600-800{ }^{\circ} \mathrm{C}$, the well-dispersed NZVI catalyzes the transformation from amorphous carbon to graphitic carbon. The NZVI/PC composite prepared at $800{ }^{\circ} \mathrm{C}$ exhibited high efficiency for adsorption and dechlorination of PCBs in aqueous solution. This is attributed to the composites' high surface area, uniformly dispersed nanoscale iron, high degrees of graphitic porous carbon, and substantial amount of mesopores. The present study offers a simple and sustainable approach for the preparation of prospective NZVI/PC with high stability and reactivity from renewable resources.

KEYWORDS: Hydrochar, Nano metal, Carbon material, Biomass, Adsorption

\section{INTRODUCTION}

Reactive zerovalent metals such as iron and magnesium are known to efficiently dechlorinate carcinogenic polychlorinated biphenyls (PCBs) in groundwater. ${ }^{1,2}$ Because the dechlorination reaction initiated by ZVI is surface-mediated, nanoscale iron with high surface area is desirable to increase dechlorination efficiency. In addition, the availability of PCBs for adsorption onto the surface of ZVI is limited owing to their extremely low concentration. Therefore, ZVI supported on porous carbon is of great interest due to the strong adsorption of PCBs on carbonaceous materials. Several papers have described PCB removal from aqueous solution using NZVI/PC composites and have shown high removal efficiency due to simultaneous adsorption and dechlorination. ${ }^{3-6}$

Because of its high adsorption capacity, porous carbon has been widely used as a support of $\mathrm{Fe}$ for various other applications, including Fenton reactions and Fischer-Tropsch synthesis. ${ }^{7,8}$ The conventional preparation of NZVI/PC composites is a complicated and time-consuming process, generally involving concentrated acid oxidation of commercial PC, impregnation and chemical reduction of iron salts, and final thermal treatment in a reducing atmosphere. Besides using toxic concentrated acids and costly reducing agents $\left(\mathrm{H}_{2}\right.$ or $\left.\mathrm{NaBH}_{4}\right)$, conventional NZVI/PC preparation also suffer from the poor dispersion and mechanical stability of NZVI in the resultant NZVI/PC, which must be addressed to enable large-scale application. Therefore, it is important to seek a low-cost, simple method for preparing high-performance NZVI/PC composites.

Hydrochar, produced from hydrothermal carbonization (HTC) of biomass, has gained considerable attention due to its unique properties. ${ }^{9,10}$ Several papers have appeared regarding value-added application of hydrochars as renewable carbon materials. ${ }^{11,12}$ For instance, hydrochar was employed as a bioadsorbent for heavy metal removal from aqueous solution and exhibited high adsorption capacity compared to that of its parent biomass. ${ }^{11}$ In addition, hydrochar has served as a support for nano $\mathrm{Pt} / \mathrm{Pd}$ particles used as electrocatalysts in the oxidation of methanol and ethanol. ${ }^{13,14}$ These hydrochar applications not only lower the cost of carbon materials but also provide environmental benefits, as they are produced from renewable biomass resources. ${ }^{15}$

Here, we have developed a new strategy to prepare low-cost and highly reactive NZVI/PC. In this preparation approach,

\footnotetext{
Received: February 12, 2016

Revised: $\quad$ May 5, 2016

Published: May 16, 2016
} 
renewable hydrochar is used as the carbon source for porous carbon, and no additional reducing agent is required; both of these factors contribute to lower preparation costs. The hydrochar is then activated, and NZVI particles are formed in situ in a simultaneous single step, which also increases the composite's mechanical stability and reactivity. Furthermore, these materials have enhanced reactivity due to the Fe-catalyzed formation of graphitic structures within the composites.

In this article, we report the first low-cost preparation approach for NZVI/PC composites, using simple iron ion adsorption onto hydrochar, followed by self-reduction. The NZVI/PC composites were systematically characterized by multiple morphological and structural methods and were used to demonstrate adsorption and dechlorination of PCBs from aqueous solution. Also, based upon the composites' characterization, a formation mechanism is proposed.

\section{EXPERIMENTAL SECTION}

Preparation of NZVI/PC. Analytical grade iron(III) nitrate $\left[\mathrm{Fe}\left(\mathrm{NO}_{3}\right)_{3} \cdot 9 \mathrm{H}_{2} \mathrm{O}\right]$ and chromatographic grade acetone and $n$-hexane were used in the present study. Aroclor 1242 were purchased from Sigma-Aldrich.

In the present study, pinewood sawdust-derived hydrochar was adopted as a representative hydrochar. Detailed preparation procedures can be found elsewhere. ${ }^{16}$ Briefly, around $10 \mathrm{~g}$ of sawdust was loaded with $100 \mathrm{~mL}$ of deionized water into a $500 \mathrm{~mL}$ autoclave, and the reactor was heated to $200{ }^{\circ} \mathrm{C}$. After maintaining at $200{ }^{\circ} \mathrm{C}$ for $20 \mathrm{~min}$, the reactor was cooled to room temperature. The hydrochar was recovered as a solid residue by vacuum filtration and then washed using deionized water. The hydrochar was dried at $105{ }^{\circ} \mathrm{C}$ for $24 \mathrm{~h}$ and stored in a desiccator before use. Properties of this hydrochar are presented in Table 1 . About $2 \mathrm{~g}$ of hydrochar, with diameter less than

Table 1. Properties of the Hydrochar Used in the Present Study

\begin{tabular}{ll}
\hline & sawdust derived hydrochar $(\mathrm{PH})$ \\
\hline elemental analysis (daf, wt \%) & \\
$\mathrm{C}$ & 58.64 \\
$\mathrm{H}$ & 3.22 \\
$\mathrm{~N}$ & 0.13 \\
$\mathrm{~S}$ & 0.02 \\
$\mathrm{O}^{a}$ & 37.99 \\
proximate analysis (db, wt \%) & \\
volatile matter & 56.32 \\
fixed carbon & 39.20 \\
ash & 0.68 \\
moisture & 3.86 \\
${ }^{a}$ By difference. & \\
\hline
\end{tabular}

100 mesh, was immersed into $10 \mathrm{~mL}$ of $0.5 \mathrm{~mol} / \mathrm{L}$ iron(III) nitrate aqueous solution. The resulting mixture was ultrasonicated for $40 \mathrm{~min}$ at room temperature, followed by separation through vacuum filtration. The resultant solid residue (Fe-hydrochar) was dried at $105^{\circ} \mathrm{C}$ for $24 \mathrm{~h}$ prior to thermal treatment.

Thermal experiments were conducted in a horizontal fixed-bed tubular quartz reactor $(60 \mathrm{~mm}$ i.d., $1000 \mathrm{~mm}$ long). In each run, the sample was charged into an aluminum boat that was placed in the quartz tube. After nitrogen gas (flow rate $20 \mathrm{~mL} / \mathrm{min}$ ) was introduced into the system, the furnace was heated to the desired temperature at a heating rate of $5{ }^{\circ} \mathrm{C} / \mathrm{min}$ and held at the final temperature for $40 \mathrm{~min}$. The sample was then cooled to room temperature while still under $\mathrm{N}_{2}$ flow inside the reactor. The resultant solid product was then removed, washed several times with deionized water and ethanol, dried, and stored for further analysis. The composites (washed solid products) were designated as "FHC- $x x x$ ", where "xxx" indicates the temperature of the thermal treatment in ${ }^{\circ} \mathrm{C}$. For comparison, the hydrochar was also treated at $800{ }^{\circ} \mathrm{C}$ without iron(III) nitrate impregnation; this product was labeled as $\mathrm{HC}-800$.

Characterization Methods. The crystal properties of the composites were determined by X-ray diffraction (XRD) using a Bruker Advance D8 diffractometer (Germany). Graphite monochromatic copper radiation $(\mathrm{CuKa})$ at $40 \mathrm{kV}$ and $30 \mathrm{~mA}$ was applied over the $2 \theta$ range $10-80^{\circ}$. Raman spectra were obtained with a LabRAM HR800 from JY Horiba (Japan). The BET surface area was obtained from nitrogen adsorption isotherms at $-196{ }^{\circ} \mathrm{C}$ using an ASAP 2010 analyzer (Micromeritics, USA). Prior to the $\mathrm{N}_{2}$ sorption analysis, the sample was degassed at $150{ }^{\circ} \mathrm{C}$ for $8 \mathrm{~h}$. The surface morphology was examined by scanning electron microscopy (SEM) using a JSM 6010LA instrument (Japan) equipped with energy dispersive diffraction. TEM images were obtained using a JEM-2100 instrument (JEOL, Japan) under $80 \mathrm{kV}$ acceleration voltages. The metal content of the composites was determined by digestion in concentrated $\mathrm{HNO}_{3}$ with $30 \% \mathrm{H}_{2} \mathrm{O}_{2}$, followed by analysis using inductively coupled plasma optical emission spectroscopy (ICP-OES) PerkinElmer 3000DV (USA)..$^{17}$ As for temperature-programmed decomposition (TPD) analysis, around $2 \mathrm{~g}$ of hydrochar was used, and it was conducted in a fixed-bed tubular quartz reactor, using temperature ranging from 200 to $900{ }^{\circ} \mathrm{C}$ with a heating rate of $5{ }^{\circ} \mathrm{C} / \mathrm{min}$ and a nitrogen gas flow rate of $20 \mathrm{~mL} / \mathrm{min}$.

Reactivity of the Composite. The FHC- 600 and FHC- 800 were selected as representative materials to evaluate the reactivity of the produced composites for removal of PCBs from aqueous solutions.

Serum bottles $(50 \mathrm{~mL})$ capped with Viton stops and sealed with aluminum caps were employed for adsorption and dechlorination experiments. Two grams of composite was added to $25 \mathrm{~mL}$ of $10 \mathrm{mg} / \mathrm{L}$ PCBs aqueous solution, and the mixture was agitated on a platform shaker at $250 \mathrm{rpm}$ at room temperature. At preset intervals, $0.5 \mathrm{~mL}$ aqueous samples were removed with a glass syringe and added to $2.5 \mathrm{~mL}$ glass vessels filled with $1 \mathrm{~mL}$ of $n$-hexane. (The initial sampling interval was $2 \mathrm{~h}$, up to $24 \mathrm{~h}$, then was increased to $48 \mathrm{~h}$.) The aqueous samples were extracted with hexane on a platform shaker at $250 \mathrm{rpm}$ and $25{ }^{\circ} \mathrm{C}$ for $24 \mathrm{~h}$ followed by centrifugation for $20 \mathrm{~min}$. The hexane layer was analyzed for PCBs and their dechlorinated products by CG-MS (Agilent $7890 \mathrm{~A} / 5975 \mathrm{C}$, USA) using an HP-5 column $(5 \%$ phenyl methyl siloxane, $30 \mathrm{~m} \times 250 \mu \mathrm{m} \times 0.25 \mu \mathrm{m})$. The injected volume was $1 \mu \mathrm{L}$, with a split ratio of 30:1. The oven program was $1 \mathrm{~min}$ isothermal at $100^{\circ} \mathrm{C}$, followed by a heating rate of $2{ }^{\circ} \mathrm{C} / \mathrm{min}$ to $210^{\circ} \mathrm{C}$, and a final hold of $1 \mathrm{~min}$. The control experiment for PCB aqueous extraction by hexane without composite was performed, and the recovery efficiency was around $96.30 \%$, which was within the acceptable range.

After 6 days, the solid/liquid mixture was separated by vacuum filtration, and the recovered composite was extracted with $20 \mathrm{~mL}$ of acetone $/ n$-hexane $(\mathrm{v} / \mathrm{v}=1)$ using Soxhlet extraction equipment. The extracts were analyzed for residual $\mathrm{PCBs}$ and dechlorinated products by the GC-MS method described above.

\section{RESULTS AND DISCUSSION}

As shown in Figure 1, there is no peak in the XRD pattern of the composite obtained at $300{ }^{\circ} \mathrm{C}$, implying that no crystal phase was formed under these experimental conditions. ${ }^{18,19}$ For the composite FHC-400, two peaks at $35.40^{\circ}$ and $62.35^{\circ}$ appeared, indicating the presence of the spinel structure $\mathrm{Fe}_{2} \mathrm{O}_{3}{ }^{20}$ Because of the similarity of XRD patterns of $\gamma$ - $\mathrm{Fe}_{2} \mathrm{O}_{3}$ and $\mathrm{Fe}_{3} \mathrm{O}_{4}$, Raman analysis was conducted to identify the difference. As shown in Figure S1, the formation of $\mathrm{Fe}_{2} \mathrm{O}_{3}$ was confirmed by the appearance of characteristic peaks at 257 and $480 \mathrm{~cm}^{-1}$, and no characteristic peak of $\mathrm{Fe}_{3} \mathrm{O}_{4}$ was observed. ${ }^{21-23}$ These two peaks were enhanced with increasing temperature from 400 to $600{ }^{\circ} \mathrm{C}$, and other $\mathrm{Fe}_{2} \mathrm{O}_{3}$ peaks $\left(30.04^{\circ}, 43.42^{\circ}\right.$, and $57.31^{\circ}$ ) were also observed within this temperature range. With further temperature increases, the peaks of $\mathrm{Fe}_{2} \mathrm{O}_{3}$ became weaker and disappeared almost completely in the XRD pattern of FHC-800. 


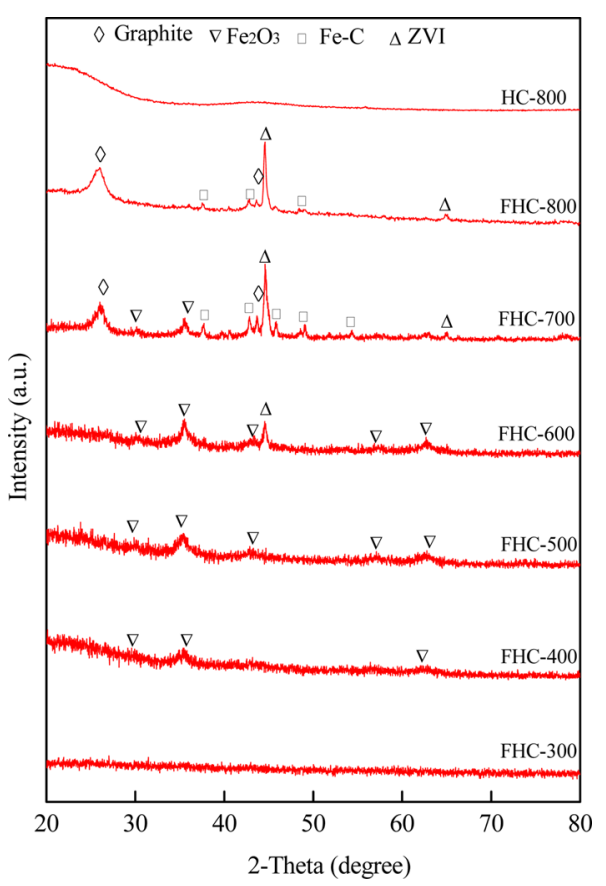

Figure 1. XRD patterns of FHC composites and HC-800.

The characteristic peaks $2 \theta=44.57^{\circ}$ and $64.94^{\circ}$ of $\mathrm{ZVI}$ appeared at treatment temperatures above $500{ }^{\circ} \mathrm{C}$; these two peaks correspond to the (110) and (200) plane reflections of the ZVI with a body centered cubic (bcc) structure. ${ }^{24}$ The calculated ZVI particle sizes using Scherrer's equation were 8.0, 8.5, and $8.9 \mathrm{~nm}$ in FHC-600, FHC-700, and FHC-800, respectively. ${ }^{24}$ The increase of the NZVI particle size with temperature is believed to result from enhanced aggregation from 600 to $800{ }^{\circ} \mathrm{C}$. In addition, the peaks at $2 \theta=25.98$ and $43.73^{\circ}$, which correspond to the (002) and (100) plane diffraction peaks of graphite, were clearly observed in the XRD spectra of FHC-700 and FHC-800. The interlayer spacing of the (002) plane was $0.342 \mathrm{~nm}$, and the calculated graphitization degree parameter $g$ was 0.233 and 0.236 for FHC-700 and FHC-800, respectively, implying that substantial amounts of well-developed graphitic structure were present in these samples. ${ }^{25}$ As a comparison, no reflection of crystal metal phase or graphitic structure was observed in the XRD pattern of HC-800. The deviation of the baseline at small angles $\left(<30^{\circ}\right)$ in the XRD pattern originated from the amorphous carbonaceous structure of $\mathrm{HC}-800 .^{26}$ All of the above observations indicate clearly that the transformation of carbon from amorphous phase to graphitic structure was catalyzed by in situ formation of NZVI, which is highly dependent on temperature.

It is worth noting that diffraction peaks corresponding to iron carbides $\left(2 \theta=37.78^{\circ}, 42.81^{\circ}, 45.87^{\circ}, 48.56^{\circ}\right.$, and $\left.49.17^{\circ}\right)$ were observed in the composites when the temperature was $\geq 700{ }^{\circ} \mathrm{C}$. It is known that nanometal-supported porous carbon suffers from low mechanical stability due to weak interactions between the metal and support carbon. One strategy to improve this stability is to form metal-carbon compounds. ${ }^{27}$ In the present study, the formation of iron carbide indicates high mechanical stability of the composites. ${ }^{27}$

The analysis results of BET surface areas, total pore volumes, and average pore sizes of the composites are summarized in Table 2. Figure 2 shows $\mathrm{N}_{2}$ adsorption-desorption isotherms of HC-800, FHC-600, FHC-700, and FHC-800. In comparison with $\mathrm{HC}-800$ and FHC-400, the BET surface areas of NZVI/
Table 2. Detailed Properties of the Composites Obtained from Different Thermal Treatments ${ }^{a}$

$\begin{array}{ccccc}\text { sample } & \begin{array}{c}S_{\mathrm{BET}} \\ \left(\mathrm{m}^{2} / \mathrm{g}\right)\end{array} & \begin{array}{c}\text { pore volume } \\ \left(\mathrm{cm}^{3} / \mathrm{g}\right)\end{array} & \begin{array}{c}\text { average pore size } \\ (\mathrm{nm})\end{array} & \begin{array}{c}\text { metal content } \\ (\text { wt } \%)\end{array} \\ \text { FHC-400 } & 32 & 0.04 & 1.24 & 24.32 \\ \text { FHC-500 } & 423 & 0.23 & 1.67 & 13.59 \\ \text { FHC-600 } & 459 & 0.26 & 1.72 & 12.45 \\ \text { FHC-700 } & 416 & 0.28 & 1.84 & 15.36 \\ \text { FHC-800 } & 472 & 0.22 & 1.79 & 8.22 \\ \text { HC800 } & 20 & 0.04 & 1.43 & \text { ND }\end{array}$

${ }^{a} \mathrm{ND}$ : not detected.

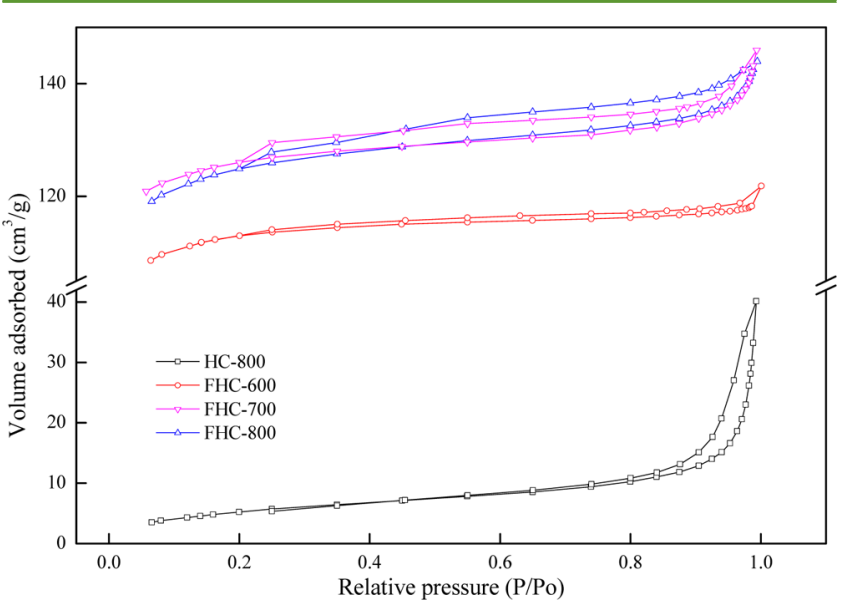

Figure 2. $\mathrm{N}_{2}$ adsorption/desorption isotherms of FHC-600, 700, 800, and HC- 800 .

PC composites were significantly increased by the addition of iron(III) nitrate. This indicates that iron(III) nitrate served as an activation agent during hydrochar thermal treatment within the temperature range of $500-800{ }^{\circ} \mathrm{C}$. The slight decrease of pore volume and surface area of NZVI/PC composites as the temperature increased from 600 to $800{ }^{\circ} \mathrm{C}$ is ascribed to the partial collapse and combination of pores caused by high temperature. As can be seen in Figure 2, FHC-600, FHC-700, and FHC-800 exhibited a type IV nitrogen adsorption/desorption isotherm according to the IUPAC classification. The hysteresis loop at higher relative pressure $\left(P / P_{0}=0.20-0.95\right)$ between adsorption and desorption isotherms indicates the presence of mesopores, especially for the FHC-800 composite. ${ }^{28}$ The formation of mesopores is attributed in part to carbon removal by in situ formed NZVI; the same catalytic reaction has been observed in an aerogel carbonization process. ${ }^{25,29}$ Furthermore, the upward tendency at high relative pressure $\left(P / P_{\mathrm{o}}=0.95-1.00\right)$ results from the adsorption of the macropores and accumulation of carbon particles. In addition, the hysteresis loop of $\mathrm{H} 3$ showed nonlimiting adsorption at high relative pressure, suggesting the slit-shaped porous nature of the FHC composite. ${ }^{28}$

Figure 3 shows SEM images of HC-800 and FHC-800. As shown in Figure 3a, HC-800 has relatively smooth surfaces, with no clear porous structure. In contrast, pores of different sizes and shapes can be observed clearly on the irregular external surfaces of FHC-800 (Figure 3b). Figure 3c shows a twodimensional X-ray mapping of $\mathrm{FHC}-800$ in a selected region to investigate the distribution of $\mathrm{C}, \mathrm{Fe}$, and $\mathrm{O}$ elements in the PC matrix. All three elements were nearly uniformly dispersed throughout the PC matrix.

The TEM images of FHC-800 (shown in Figure 4) provide evidence of the well-dispersed morphology of iron particles. 

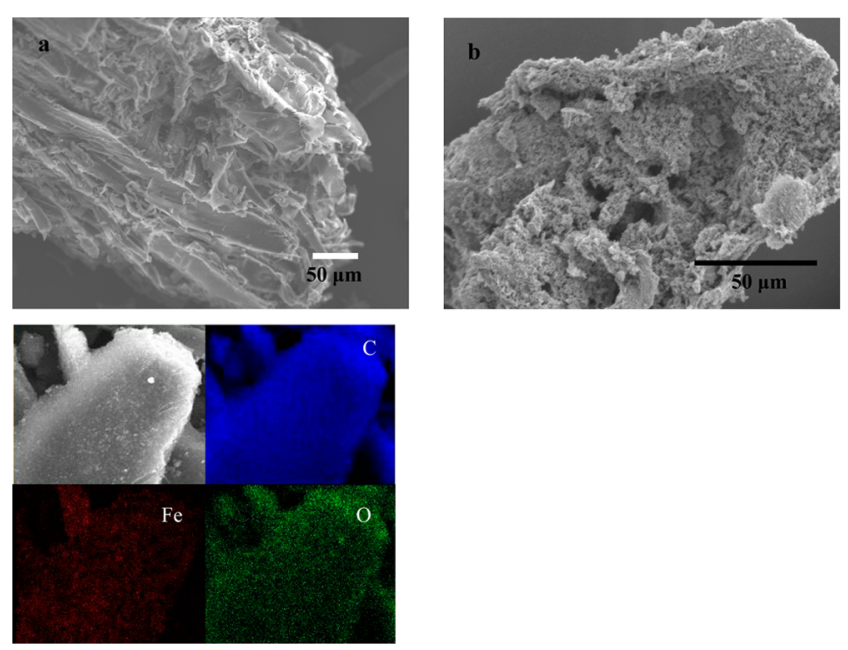

Figure 3. SEM images of (a) HC-800, (b) FHC-800, and (c) corresponding mapping of elemental $\mathrm{Fe}, \mathrm{C}$, and $\mathrm{O}$ in FHC-800.
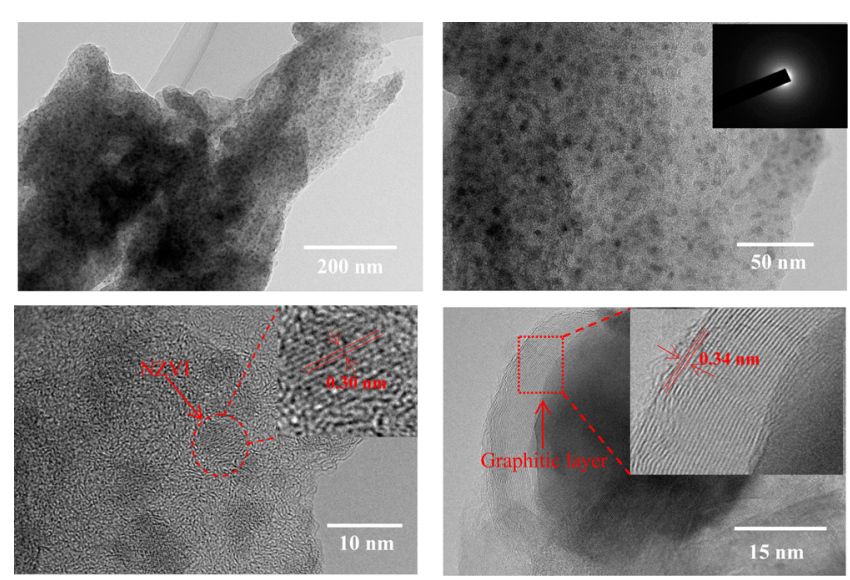

Figure 4. TEM micrographs of FHC-800 at different viewing angles and magnifications.

According to calculations using Scherrer's equation, these particles have a mean size of $8.9 \mathrm{~nm}$. In addition, the TEM images FHC-800 further reveal the pore structure of FHC-800 and clearly show two types of carbon phases within the porous carbon: crystalline graphitic carbon (around nano $\mathrm{Fe}$ regions) and amorphous carbon (Figure 4). Compared to FHC-600, the graphitic structure was significantly increased in FHC-800, confirming that high temperature is vital for Fe catalytic transformation from amorphous carbon to graphitic carbon. The well-distributed NZVI within the highly graphitic structure of PC suggests the high reactivity of the ZVI. ${ }^{30}$

Figure 5 shows the TPD curves for the four main gas products evolved during the thermal treatment of hydrochar and $\mathrm{Fe}$-hydrochar. The majority of the gas product was $\mathrm{H}_{2}$ and $\mathrm{CO}$ for both hydrochar and Fe-hydrochar. The formation of $\mathrm{CO}$ and $\mathrm{CO}_{2}$ indicates that substantial amounts of oxygencontaining functional groups were present in the hydrochar. Methane $\left(\mathrm{CH}_{4}\right)$ likely originates from the decomposition of methyl groups attached to aromatic units of the hydrochar. For hydrochar, gas yields significantly increased at temperatures above $600{ }^{\circ} \mathrm{C}$, except $\mathrm{CH}_{4}$, which reached its maximum yield at $600{ }^{\circ} \mathrm{C}$ and then decreased at higher temperatures. In the case of Fe-hydrochar, iron(III) nitrate addition significantly changed the gas evolution behavior during thermal treatment. The Fe-hydrochars gave increased gas yields overall and especially
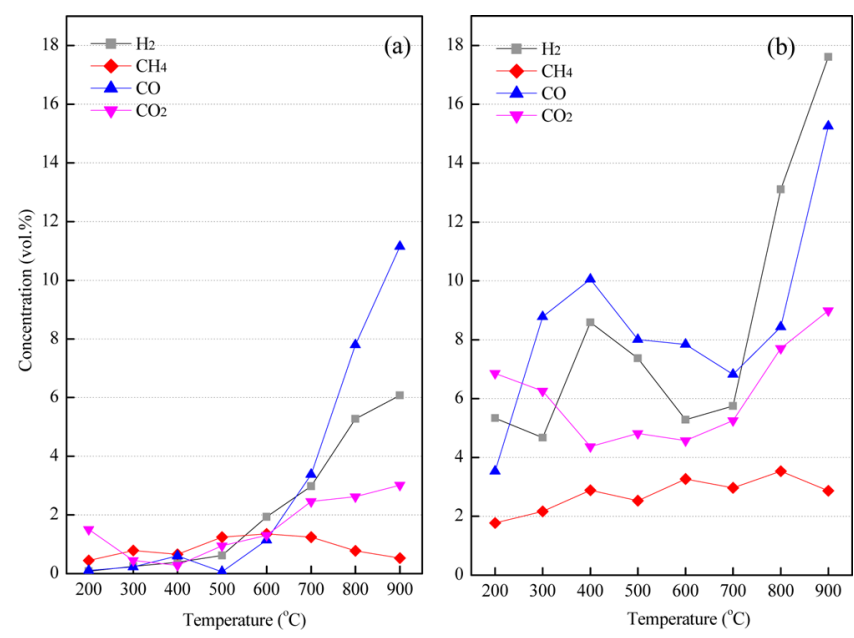

Figure 5. Gas evolution from (a) hydrochar and (b) Fe-hydrochar at different temperatures.

showed higher gas evolution at lower treatment temperatures. In addition, yields of $\mathrm{H}_{2}$ and $\mathrm{CO}$ first increased from 200 to $400{ }^{\circ} \mathrm{C}$, then decreased within the temperature range of 400 to $700{ }^{\circ} \mathrm{C}$, and again increased at temperatures above $700{ }^{\circ} \mathrm{C}$. The highest yields of $\mathrm{H}_{2}$ and $\mathrm{CO}$ were achieved at a treatment temperature of $900{ }^{\circ} \mathrm{C}$, while the yields of $\mathrm{CH}_{4}$ were relatively constant over the entire temperature range of 200 to $900{ }^{\circ} \mathrm{C}$.

On the basis of these chemical characterization results and information regarding textural structure, a formation mechanism of NZVI/PC composites can be proposed. ${ }^{31-33}$ The ultrasonic treatment and unique surface properties of the hydrochar results in well-dispersed iron ions within the hydrochar matrix by means of physical adsorption and coordination (confirmed by Figure S2). During the thermal process, the iron ions are first hydrolyzed to iron(III) hydroxide. With further heating, the iron(III) hydroxide is dehydrated and transformed into iron(III) oxide, which is then reduced to ZVI mainly by $\mathrm{H}_{2}$, $\mathrm{CO}$, and amorphous carbon at temperatures higher than $600{ }^{\circ} \mathrm{C}^{34}$ The reductions of iron(III) oxide by $\mathrm{H}_{2}, \mathrm{CO}$, and amorphous carbon are supported by the decreased yield of $\mathrm{H}_{2}$ and $\mathrm{CO}$ from $\mathrm{Fe}$-hydrochar treated at $500{ }^{\circ} \mathrm{C}$ and significantly increased $\mathrm{CO}_{2}$ yield compared to that from hydrochar, respectively. The enhanced gas formation from Fe-hydrochar creates large numbers of pores within the derived composite. In addition, reduction of iron(III) oxide by amorphous carbon contributes to the increase of surface area and formation of mesopore structures. ${ }^{35}$ Subsequently, the in situ formed NZVI induces the transformation from amorphous carbon to a more graphitic structure at temperatures above $600{ }^{\circ} \mathrm{C}$. The formation mechanism of NZVI/PC composite can be mainly described in the following equations:

Hydrochar activation/NZVI formation:

(1) Hydrolysis of $\mathrm{Fe}^{3+}$

$\mathrm{Fe}\left(\mathrm{NO}_{3}\right)_{3}+3 \mathrm{H}_{2} \mathrm{O}=\mathrm{Fe}(\mathrm{OH})_{3}+3 \mathrm{HNO}_{3}$

(2) Dehydration of $\mathrm{Fe}(\mathrm{OH})_{3}$

$2 \mathrm{Fe}(\mathrm{OH})_{3}=\mathrm{Fe}_{2} \mathrm{O}_{3}+3 \mathrm{H}_{2} \mathrm{O}$

(3) Reduction of iron oxide $\left(T \geq 500{ }^{\circ} \mathrm{C}\right)$

(a) $\mathrm{Fe}_{2} \mathrm{O}_{3}+3 \mathrm{H}_{2}=2 \mathrm{Fe}+3 \mathrm{H}_{2} \mathrm{O}$ (reduction by $\mathrm{H}_{2}$ )

(b) $\mathrm{Fe}_{2} \mathrm{O}_{3}+3 \mathrm{CO}=2 \mathrm{Fe}+3 \mathrm{CO}_{2} \quad$ (reduction by $\mathrm{CO}$ ) 
(c) $2 \mathrm{Fe}_{2} \mathrm{O}_{3}+3 \mathrm{C}=4 \mathrm{Fe}+3 \mathrm{CO}_{2} \quad$ (reduction by $\mathrm{C}$ )

NZVI catalyzing $\left(T \geq 600^{\circ} \mathrm{C}\right)$

$$
\text { amorphous carbon } \rightarrow \text { graphite (Fe catalysis) }
$$

In the present study, the uniform dispersion of NZVI was achieved by well-dispersed metal ions within the hydrochar matrix. During thermal treatment, these well-dispersed ions are self-reduced to NZVI by hydrochar-derived $\mathrm{H}_{2}, \mathrm{CO}$, and amorphous carbon. Thus, the NZVI is formed in situ and is supported on the hydrochar-derived porous carbon. The preparation approach in the present study well overcomes the drawbacks of conventional preparation of NZVI/PC such as poor dispersion of NZVI and high cost.

Waste PCBs typically occur in the environment as mixtures of different chlorine-substituted PCBs. In this study, Aroclor 1242 (di-, tri-, tetra-, and penta-chlorinated PCBs) was adopted as a representative PCB sample. Individual chlorinated PCBs, selected to represent different classes of compounds, were chosen for analysis. For example, 2,3- and 2,6'-dichloro-1,1'-biphenyl represented dichlorinated biphenyls (2CB); 2,5,5'- and 2,3,4trichloro-1,1'-biphenyl represented trichlorinated biphenyls (3CB); 2,3,4', $6^{\prime}$ - and 2,4,4',6-tetrachloro-1,1'-biphenyl represented tetra-chlorinated biphenyls (4CB); 2,3,4,4', $5^{\prime}-$ and $2,3^{\prime}, 4^{\prime}, 5,6^{\prime}$-penta-1,1'-biphenyl represented penta-chlorinated biphenyls (5CB). Figure 6 shows the removal rates of different

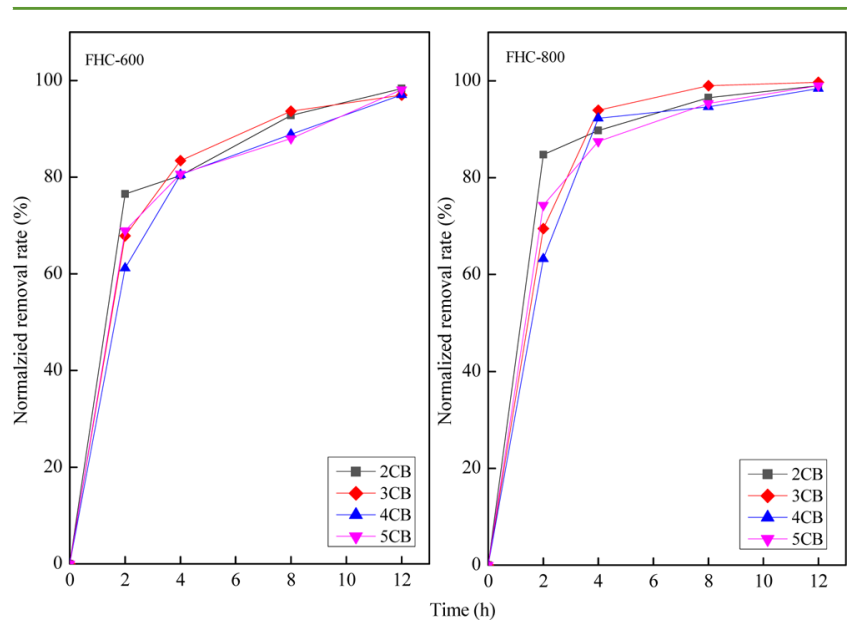

Figure 6. Removal rates of PCBs by FHC- 600 and FHC- 800 as a function of time at room temperature (PCBs concentration $10 \mathrm{mg} / \mathrm{L}$; dose $80 \mathrm{~g} / \mathrm{L}$ ).

chlorine-substituted PCBs in aqueous solution when treated with FHC-600 and FHC-800. More than 91\% of PCBs were removed within $12 \mathrm{~h}$ by both FHC-600 and FHC-800. Initial rates of removal were higher with FHC-800 compared to that with FHC-600. This is attributed to the greater presence of mesopores in FHC-800, which provide transport pathways for microporous adsorption, and the slit-shaped porous shapes, which are easily accessed and filled efficiently. ${ }^{36-38}$ Pseudofirst-order (eq 7) and pseudo-second-order (eq 8) equations were employed to investigate the PCBs' removal behavior with FHC-600 and FHC-800.

$$
\begin{aligned}
& \log \left(q_{e}-q_{t}\right)=\log q_{e}-\frac{k_{1} t}{2.303} \\
& \frac{t}{q_{t}}=\frac{1}{k_{2} q_{e}^{2}}+\frac{t}{q_{e}}
\end{aligned}
$$

where $q_{\mathrm{t}}$ and $q_{\mathrm{e}}(\mathrm{mg} / \mathrm{g})$ are the amount of adsorbed PCBs at time $t(\mathrm{~h})$ and time of equilibrium $k_{1}(1 / \mathrm{h})$ and $k_{2}(\mathrm{~g} / \mathrm{mgh})$ are the rate constants for pseudo-first-order and pseudo-secondorder adsorption kinetics, respectively.

Table 3 shows the parameters derived from application of pseudo-first-order and pseudo-second-order kinetics for PCB removal ( $\mathrm{PCB}$ removal rate is taken as the average removal rate of the representative compounds $2 \mathrm{CB}, 3 \mathrm{CB}, 4 \mathrm{CB}$, and $5 \mathrm{CB}$ ). PCB removal by FHC- 600 and FHC- 800 are satisfactorily described by the pseudo-second-order equation as a result of synergistic combination of the PCBs' adsorption and dechlorination. The kinetic constants calculated from the pseudo-secondorder equation are consistent with the fast removal of PCBs from aqueous solution by the composites FHC-600 and FHC-800. However, due to higher dechlorination rates, the pseudo-firstorder fitting was slightly better for FHC-800 than FHC-600 ( $R^{2}$ was 0.98 and 0.96 for FHC-800 and FHC-600, respectively).

Figure 7 shows the dechlorination rates of the representative compounds of different-chlorinated PCBs. As can be seen,

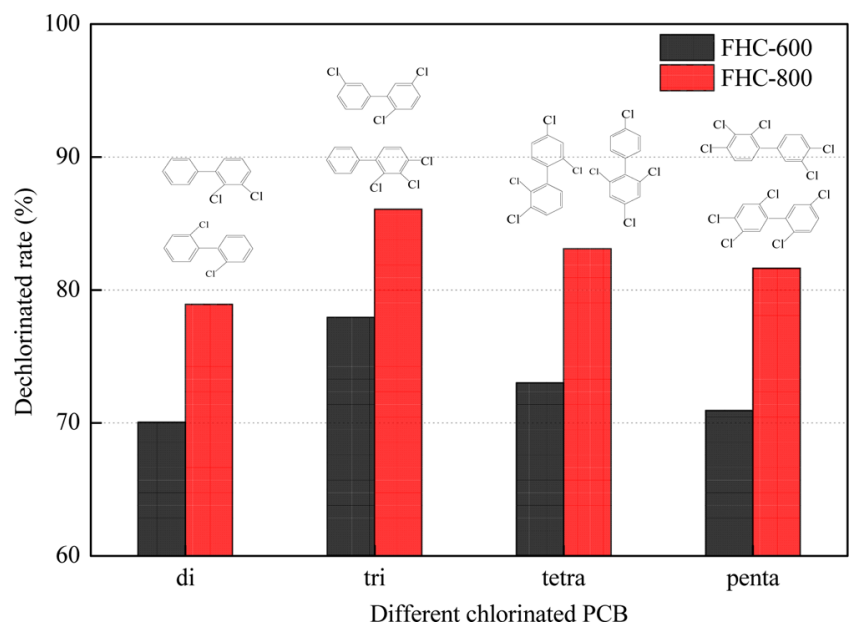

Figure 7. Dechlorination rates of different substituted PCBs by FHC600 and FHC- 800 at room temperature (dose $80 \mathrm{~g} / \mathrm{L}$; reaction time 6 days).

trichlorinated biphenyls have the highest dechlorination rates of about $78 \%$ and $86 \%$ when using FHC-600 and FHC-800, respectively, for 6 days at room temperature. Accounting for the inevitable transformation of highly chlorinated PCBs to these less highly chlorinated representative compounds, it can be concluded that the actual dechlorination rates of PCBs was higher than the dechlorination rates observed here. In addition,

Table 3. Pseudo-first-order and Pseudo-second-order Kinetic Parameters for PCB Removal by FHC-600 and FHC-800

equations

parameters

FHC-600

FHC-800 $k_{1}(\mathrm{~h})$

0.28

0.33 pseudo-first-order

$q_{\mathrm{e}}(\mathrm{mg} / \mathrm{g})$

58.79

43.49
$R^{2}$

0.96

0.98

$k_{2}(\mathrm{~g} / \mathrm{mgh})$
$6.26 \times 10^{-4}$
$6.26 \times 10^{-4}$

$6.26 \times 10^{-4}$ pseudo-second-order

$q_{\mathrm{e}}(\mathrm{mg} / \mathrm{g})$

105.26

105.26
0.99

0.99 
only small amounts of biphenyl, the completely dechlorinated product, were detected in the aqueous solution, suggesting that the dechlorinated products preferentially adsorbed on the composites rather than diffusing into the aqueous solution.

The reduction of PCBs by NZVI generally involves mass transport of the PCBs from aqueous solution to the NZVI surface area, where surface reduction reactions occur. The efficient room temperature dechlorination of PCBs with FHC-800 and FHC-600 in the present study are ascribed to the higher surface area of NZVI and enhanced contacting between the PCBs and NZVI, due to the highly graphitic nature of PC. ${ }^{34}$ Because of the crystalline graphitic structure in the FHC-800 matrix, electrons of the NZVI available for electrochemical reduction reactions can readily transport throughout the structure and therefore expand the reactive surface area available for reduction.

\section{CONCLUSIONS}

In this study, a simple and effective strategy for preparing NZVI/PC composites was developed using hydrochar and iron(III) nitrate as precursors. The metal ions are dispersed uniformly throughout the hydrochar matrix, and during subsequent thermal treatment, the iron ions are self-reduced to NZVI. In addition, when heated in the temperature range of $600-800{ }^{\circ} \mathrm{C}$, the in situ formed NZVI catalyzes the formation of graphitic structures and promotes the formation of mesopore structures. The NZVI/PC composites showed high performance for PCB removal from aqueous solutions. The synergistic adsorption and dechlorination of PCBs with NZVI/PC was well described by pseudo-second-order kinetic equations.

In the present study, renewable hydrochar was used as the precursor of the porous carbon, and no additional reducing agent was required. In addition, activation of the hydrochar and formation/deposition of NZVI were realized simultaneously through a one-step process. This approach offers a simple, lowcost, and green production method for NZVI/PC composites, which have the potential for wide applicability and provide significant environmental and cost benefits.

\section{ASSOCIATED CONTENT}

\section{S Supporting Information}

The Supporting Information is available free of charge on the ACS Publications website at DOI: 10.1021/acssuschemeng.6b00306.

Raman spectra of the composites FHC-400, 500, 600, and 700 and SEM images of Fe-hydrochar and corresponding mapping of carbon, iron, and oxygen (PDF)

\section{AUTHOR INFORMATION}

\section{Corresponding Author}

*Tel: +86 10 62915966. Fax: +8610 62915966. E-mail: zgliu@ rcees.ac.cn (Zhengang Liu).

\section{Notes}

The authors declare no competing financial interest.

\section{ACKNOWLEDGMENTS}

We gratefully acknowledge financial support for Zhengang Liu from the "100 Talents" Program of the Chinese Academy of Sciences. We also acknowledge support from the State Natural Sciences Fund, China (Project No. 3190021501405).

\section{REFERENCES}

(1) Zhang, W. Nanoscale iron particles for environmental remediation: an overview. J. Nanopart. Res. 2003, 5, 323-332.
(2) Fang, Y.; Al-Abed, S. R. Partitioning, desorption and dechlorination of a $\mathrm{PCB}$ congener in sediment slurry supernatants. Environ. Sci. Technol. 2007, 41, 6253-6258.

(3) Gaspar, D. J.; Lea, A. S.; Engelhard, M. H.; Baer, D. R.; Miehr, R.; Tratnyek, P. G. Evidence for localization of reaction upon reduction of carbon tetrachloride by granular iron. Langmuir 2002, 18, 7688-7693.

(4) Saleh, N.; Siik, K.; Liu, Y.; Phenrat, T.; Dufour, B.; Matyjaszewski, K.; Tilton, R. T.; Lowry, G. V. Surface modifications enhance nanoiron transport and NAPL targeting in saturated porous media. Environ. Eng. Sci. 2007, 24, 45-57.

(5) Choi, H.; Al-Abed, S. R.; Agarwal, S.; Dionysiou, D. D. Synthesis of reactive nano-Fe/Pd bimetallic system-impregnated activated carbon for the simultaneous adsorption and dechlorination of PCBs. Chem. Mater. 2008, 20, 3649-3655.

(6) Yoon, T. H.; Benzerara, K.; Ahn, S.; Luthy, R. G.; Tyliszczak, T.; Brown, G. E. Nanometer-scale chemical heterogeneities of black carbon materials and their impacts on PCB sorption properties: soft Xray spectromicroscopy study. Environ. Sci. Technol. 2006, 40, 59235929.

(7) Ramirez, J. H.; Maldonado-Hodar, F. J.; Perez-Cadenas, A. F.; Moreno-Castilla, C. C.; Costa, A.; Madeira, L. M. Azo-dye orange II degradation by heterogeneous Fenton-like reaction using carbon-Fe catalysts. Appl. Catal., B 2007, 75, 312-323.

(8) Ma, W.; Kugler, E. L.; Dadyburjor, D. B. Potassium effect on activated-carbon-supported iron catalysts for Fischer-Tropsch synthesis. Energy Fuels 2007, 21, 1832-1842.

(9) Libra, J. A.; Ro, K. S.; Kammann, C.; Funke, A.; Berge, N. D.; Neubauer, Y.; Titirici, M. M.; Fuhner, C.; Bens, O.; Kern, J.; Emmerrich, K. H. Hydrothermal carbonization of biomass residuals: a comparative review of the chemistry, processes and applications of wet and dry pyrolysis. Biofuels 2011, 2, 71-106.

(10) Liu, Z.; Zhang, F.; Wu, J. Characterization and application of chars produced from pinewood pyrolysis and hydrothermal treatment. Fuel 2010, 89, 510-514.

(11) Liu, Z.; Zhang, F. Removal of lead from water using biochars prepared from liquefaction of biomass. J. Hazard. Mater. 2009, 167, 933-939.

(12) Kambo, H. S.; Dutta, A. A comparative review of biochar and hydrochar in terms of production, physic-chemical properties and application. Renewable Sustainable Energy Rev. 2015, 45, 359-378.

(13) Kim, P.; Joo, J.; Kim, W.; Kim, J.; Song, I. K.; Yi, J. Graphtitic sperecal carbon as support for a PtRu-alloy catalyst in the methanol electro-oxidation. Catal. Lett. 2006, 112, 213-218.

(14) Sevilla, M.; Lota, G.; Fuertes, A. B. Saccharide-based graphitic carbon nanocoils as supports for PtRu nanoparticles for methanol electrooxidation. J. Power Sources 2007, 171, 546-551.

(15) Roberts, K. G.; Gloy, B. A.; Joseph, S.; Scott, N. R.; Lehmann, J. Life cycle assessment of biochar systems: estimating the energetic, economic, and climate change potential. Environ. Sci. Technol. 2010, 44, 827-833.

(16) Liu, Z.; Quek, A.; Balasubramanian, R. Production of solid biochar fuel from waste biomass by hydrothermal carbonization. Fuel 2013, 103, 943-949.

(17) USEPA. Test Methods for Evaluating Solid Waste, Physical/ Chemical Method, 2nd ed.; EPA SW 846; USEPA: Washington, DC,1996.

(18) Uegami, M.; Kawano, J.; Okita, T.; Fujii, Y.; Okinaka, K.; Kayuka, K.; Yatagi, S. Iron Particles for Purifying Contaminated Soil or Groundwater. U.S. Patent Application 7022256, 2006.

(19) Hoch, L. B.; Mack, E. J.; Hydutsky, B. W.; Hershman, J. M.; Skluzacek, J. M.; Mallouk, T. E. Carbothermal synthesis of carbonsupported nanoscale zero-valent iron particles for the remediation of hexavalent chromium. Environ. Sci. Technol. 2008, 42, 2600-2605.

(20) Fuertes, A. B.; Tartaj, P. A facile route for the preparation of superparamagnetic porous carbons. Chem. Mater. 2006, 18, 16751679.

(21) Fondell, M.; Johansson, F.; Gorgoi, M.; von Fieandt, L.; Boman, M.; Lindblad, A. Phase control of iron oxides grown in nano-scale 
structures on $\mathrm{FTO}$ and $\mathrm{Si}(100)$ : hematite, maghemite and magnetite. Vacuum 2015, 117, 85-90.

(22) Wan, Y.; Shi, X.; Xia, H.; Xie, J. Synthesis and characterization of carbon-coated $\mathrm{Fe}_{3} \mathrm{O}_{4}$ nanoflakes as anode material for lithium-ion batteries. Mater. Res. Bull. 2013, 48, 4791-4796.

(23) Jin, C.; Yao, Q.; Li, J.; Fan, B.; Sun, Q. Fabrication, superhydrophobicity, and microwave absorbing properties of the magnetic $\gamma-\mathrm{Fe}_{2} \mathrm{O}_{3} /$ bamboo composites. Mater. Des. 2015, 85, 205210.

(24) Cullity, B. D.; Stock, S. R. Elements of X-ray Diffraction, 3rd ed. Prentice-Hall: New York, 2001.

(25) Maldonado-Hodar, F. J.; Moreno-Castilla, C.; Rivera-Utrilla, J.; Hanzawa, Y.; Yamada, Y. Catalytic graphitization of carbon aerogels by transition metals. Langmuir 2000, 16, 4367-4373.

(26) Mochidzuki, K.; Soutric, F.; Tadokoro, K.; Antal, M. J.; Toth, M.; Zelei, B.; Varhegyi, G. Electric and physical properties of carbonized charcoals. Ind. Eng. Chem. Res. 2003, 42, 5140-5151.

(27) Tian, J.; Sun, G.; Jiang, L.; Yan, S.; Mao, Q.; Xin, Q. Highly stable PtRuTiOx/C anode electrocatalyst for direct methanol fuel cell. Electrochem. Commun. 2007, 9, 563-568.

(28) Sing, K. S. W.; Everett, D. H.; Hanl, R. A. W.; Moscou, L.; Pierotti, R. A.; Rouquerol, J.; Siemieniewska, T. Reporting physisorption data for gas/solid system with special reference to the determination of surface area and porosity. Pure Appl. Chem. 1985, 57, 603-619.

(29) Lu, A. H.; Li, W. C.; Matoussevitch, N.; Spliethoff, B.; Bonnemann, H.; Schuth, F. Highly stable carbon-protected cobalt nanoparticles and graphite shell. Chem. Commun. 2005, 98-100.

(30) Garcia-Garcia, A.; Gregorio, A.; Franco, C.; Pinto, F.; Boavida, D.; Gulyurtlu, I. Unconverted chars obtained during biomass gasification on a pilot-scale gasifier as a source of activated carbon production. Bioresour. Technol. 2003, 88, 27-32.

(31) Garcia, L.; Salvador, M. L.; Arauzo, J.; Bilbao, R. Catalytic steam gasification of pine sawdust: effect of catalyst weight/biomass flow rate and steam/biomass ratios on gas production and composition. Energy Fuels 1999, 13, 851-859.

(32) Sun, Y.; Ryoji, N.; Masaki, T.; Nobuo, T.; Tadaoa, M.; Kazuyuki, O. Catalytic degradation of polychlorinated biphenyls with activated carbon-supported iron. Kankyo Kagaku 2005, 15, 259-268.

(33) Zhang, J.; Toghiani, H.; Mohan, D.; Pittman, C. U.; Toghiani, R. $\mathrm{K}$. Product analysis and thermodynamic simulations from the pyrolysis of several biomass feedstocks. Energy Fuels 2007, 21, 2373-2385.

(34) Dufour, A.; Girods, P.; Masson, E.; Rogaume, Y.; Zoulalian, A. Synthesis gas production by biomass pyrolysis: effect of reactor temperature on product distribution. Inter. Int. J. Hydrogen Energy 2009, 34, 1726-1734.

(35) Fu, R.; Baumann, T. F.; Cronin, S.; Dresselhaus, G.; Dresselhaus, M. S.; Satcher, J. H. Formation of graphitic structures in cobalt- and nickel-doped carbon aerogels. Langmuir 2005, 21, 2647-2651.

(36) Yoon, T. H.; Benzerara, K.; Ahn, S.; Luthy, R. G.; Tyliszczak, T.; Brown, G. E. Nanometer-scale chemical heterogeneities of black carbon materials and their impacts on PCBs sorption properties: soft X-ray spectromicroscopy study. Environ. Sci. Technol. 2006, 40, 59235929.

(37) Guo, Y.; Kaplan, S.; Karanfil, T. The significance of physical factors on the adsorption of polyaromatic compounds by activated carbons. Carbon 2008, 46, 1885-1891.

(38) Choi, H.; Al-Abed, S. R; Agarwal, S. Catalytic role of palladium and relative reactivity of substituted chlorines during adsorption and treatment of PCBs on reactive activated carbon. Environ. Sci. Technol. 2009, 43, 7510-7515. 